\title{
Processo produtivo da juta e malva na perspectiva do desenvolvimento sustentável
}

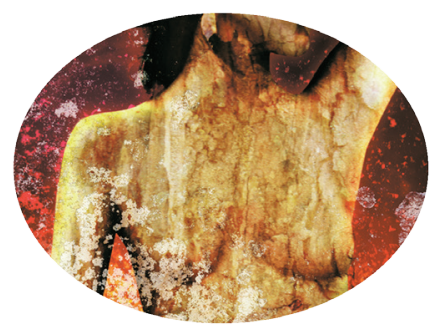

Sandra Helena da Silva* Therezinha de Jesus Pinto Fraxe**

\section{Resumo}

O presente estudo tem por objetivo promover a discussão sobre o processo produtivo da juta e malva na perspectiva do desenvolvimento sustentável. Como abordagem metodológica, utilizou-se a pesquisa exploratória que pretende, por meio da revisão bibliográfica, deslindar alguns conceitos e elementos referentes a essa temática, como a noção de desenvolvimento sustentável e o processo produtivo da juta e malva. Nos estudos preliminares identificouse que o desenvolvimento sustentável é entendido como o processo em que permite satisfazer as necessidades da população atual, sem comprometer a capacidade de atender às gerações futuras. Sobre esse termo existem consensos e divergências teóricas, visto que pressupõe incrementos no desenvolvimento de tecnologias e na busca de estratégias para melhor aproveitamento dos recursos naturais, sem, contudo, aprofundar ou propor modificações nas relações de produção, baseadas no sistema capitalista. A noção de desenvolvimento sustentável apresenta diversas dimensões e critérios que podem nortear a análise de diversos processos produtivos, questões socioambientais, atividades laborativas, entre outras. Neste estudo foram trabalhadas oito dimensões que contribuíram para uma breve análise da (in)sustentabilidade da cultura da juta e malva. Verificaram-se as fragilidades das dimensões sociais, econômicas e

\footnotetext{
* Doutoranda em Ciências do Ambiente e Sustentabilidade da Amazônia. Docente no Curso de Serviço Social - ICSEZU/Ufam. E-mail: sandrahsf@gmail.com

*** Professora associada da Universidade Federal do Amazonas; coordenadora do Núcleo de Socioeconomia - Nusec. E-mail: tecafraxe@uol.com.br
} 
políticas para o desenvolvimento sustentável nessa cultura. Nesse contexto de desenvolvimento sustentável, o foco da discussão não é a modificação do sistema capitalista e as relações de produção nele presente, mas como garantir que a preservação dos ecossistemas, da biodiversidade, para o contínuo crescimento econômico. O processo produtivo da juta e malva se encontra imbricado nesse movimento, que segue a lógica do capital, de apropriação e mercantilização dos recursos naturais, além do processo de inclusão dos trabalhadores rurais a essa mesma lógica. Está em debate como criar estratégias para aumentar a produtividade dessa cultura, desenvolvimento de tecnologias, melhorias das relações técnicas de produção, mas em contrapartida esses povos continuam sendo vítimas das situações de exploração e desigualdade que vive a sociedade brasileira, os acessos e participação às políticas publicas continuam sendo fragmentados ou até mesmo nulos. Os estudos sobre essas problemáticas são de suma importância, visto que os agricultores familiares da região do Amazonas vivem à revelia das decisões tomadas pelos governos, grandes corporações e agências internacionais, contudo são os mais atingidos.

Palavra-chave: desenvolvimento sustentável processo produtivo; juta e malva.

\section{Abstract}

This study aims to promote discussion about the production process of jute mallow and the perspective of sustainable development. As methodological approach used the exploratory research that aims to unravel through the literature review some concepts and elements relating to this subject, as the notion of sustainable development and the production process and jute mallow. In preliminary studies we found that sustainable development is understood as a process that meets the needs of the present population without compromising the ability of future generations to meet. About this term there are theoretical divergences and consensus, because that assumes increases in technology development and pursuit of strategies for better use of natural resources, without however further or propose changes in production relations, based on the capitalist system. The notion of sustainable development has many dimensions and criteria that can guide the analysis of various production processes, environmental issues, labor activities, among others. This study worked eight dimensions that contributed to a brief analysis of (un) sustainability of culture and jute mallow. There were the weaknesses of the social, political and economic sustainable development in this culture. 
In the context of sustainable development the focus of discussion is not the modification of the capitalist system and the relations of production in him this, but how to ensure the preservation of ecosystems and biodiversity to continue economic growth. The production process and jute mallow is interwoven in this movement, which follows the logic of capital, appropriation and commodification of natural resources, and the process of inclusion of rural workers to the same logic. Debate is in creating strategies to increase the productivity of this culture, technology development, improvement of technical relations of production, but in return those people remain victims of exploitation and inequality that lives in Brazilian society, access to political participation and public remain fragmented or even null. The studies on these issues are of paramount importance, since the farmers of the Amazon region live in absentia decisions taken by governments, corporations and international agencies, however, are the hardest hit.

Keyword: sustainable development; production process; jute and malva.

\section{Introdução}

Atualmente muito se fala do termo Desenvolvimento Sustentável, está na pauta das discussões acadêmicas, nos cursos de pós-graduação, na economia, na política e nas diversas esferas sociais. O desenvolvimento sustentável põe em questão atitudes como o consumo excessivo, a poluição do ar, a elevada produção de lixos orgânicos e inorgânicos. Contudo, como constituir uma sociedade sustentável sem limitar o crescimento econômico, sem reduzir a degradação ambiental, sem a produção em massa de inúmeros objetos que satisfazem os desejos de ter de uma grande parcela da sociedade de consumo?

Este artigo pretende promover uma discussão sobre o processo produtivo da juta e malva sob a perspectiva do desenvolvimento sustentável. Essa ideia surgiu nas aulas de doutorado onde se discutiu o termo e a sua complexidade, saindo do entendimento de que o senso comum e a mídia nos apresentam, para entender os interesses e os meandros nele presentes. Verificou-se a possibilidade de analisar as dimensões e critérios propostos por Guimarães (1997) e Sachs (2008) na esfera do processo produtivo da juta e malva, objeto de pesquisa no doutorado, sempre com um olhar de quão sustentável ou insustentável se encontra esse processo produtivo. 
O trabalho está dividido em três partes: a primeira traz um breve ensaio sobre a juta e malva no Amazonas, em seguida é conceituado o termo desenvolvimento sustentável, na terceira parte uma análise onde se articula o processo produtivo da juta e malva às dimensões e critérios de sustentabilidade propostos pelos autores.

\section{Breve Percurso da Pesquisa}

Este estudo é resultado de uma pesquisa social de cunho exploratório, que objetivou, por intermédio de diversas leituras bibliográficas e documentais, identificar o processo produtivo da juta e malva e os aspectos relativos ao termo desenvolvimento sustentável. Optou-se pela pesquisa exploratória, para que essa pudesse fornecer elementos, desenvolver e esclarecer conceitos e ideias, com vistas a formular uma problemática mais precisa e hipóteses pesquisáveis, no que tange à temática (GIL, 1987). O levantamento bibliográfico proporcionou, por meio de uma análise qualitativa dos dados, o resgate e a reflexão sobre as variáveis referentes o processo produtivo da juta e malva, o desenvolvimento dessa cultura no Amazonas, as políticas públicas e desafios aos agricultores no cultivo a essa fibra; permitiu ainda fazer uma análise sobre a perspectiva ou não dessa cultura atrelada ao desenvolvimento sustentável.

\section{Processo Produtivo da Juta e Malva}

O baixo Amazonas é reconhecido cientificamente como o lócus no desenvolvimento da produção da cultura da juta/malva na região do Amazonas. Os textos de Homma (2010), Noda (2010) e Pinto (2010) trazem um resgate histórico e uma análise econômica dessa atividade na região. Nos estudos é possível observar os olhares e representações sociais que os homens, principais protagonistas dessa história, tinham e ainda têm sobre o processo produtivo dessas fibras, os desafios, as perspectivas, relações de trabalho e as políticas públicas destinadas à agricultura familiar.

De acordo com Homma (2010), no início da década de 30 do século 20, tiveram início as primeiras experiências com o plantio da juta na Vila Amazônia, em uma comunidade ribeirinha do município de Parintins. Foram os colonos japoneses, ligados à Companhia Industrial Amazonense (Amazônia 
Sangyo Kabushiki Kaisha), que realizaram as primeiras experiências de plantio de juta na região, as sementes eram procedentes de São Paulo e do Japão. Foram diversas experiências para adaptação dessa fibra na várzea da Vila Amazônia, pelos colonos japoneses. Entretanto, o colono Ryota Oyama, por suas experiências, consegue desenvolver uma variedade de juta adaptada às características da região. Foram os cuidados e a persistência desse colono que contribuíram para o sucesso do cultivo e produção da juta na várzea amazônica.

Atualmente, a produção de juta e malva está espalhada por toda região amazônica - rio Negro, Japurá, Alto Solimões, Juruá, Tefé, Coari, Manaus, Rio Preto da Eva, Itacoatiara, Parintins, Boca do Acre, Purus, Madeira, Manacapuru, Coari (IBGE, 2010).

Em relação à produção da malva, essa fibra apresenta as mesmas peculiaridades que a juta no processo produtivo. $\mathrm{Na}$ Amazônia, era considerada como praga nas roças e por ser uma planta adaptada aos solos de baixa fertilidade. Uma vantagem na produção da malva é que esta pode ser cultivada em terra firme, ficando livre das enchentes anuais da região do Amazonas.

A produção da juta e malva nos anos 70 e 80 do século 20 representava, segundo a pesquisa de Noda (2010), a principal atividade econômica, com cerca de 25.000 agricultores familiares que cultivavam essas plantas, tendo principalmente a mão de obra familiar.

A cultura da juta e da malva se caracteriza pelo uso do trabalho manual, com auxílio de poucos instrumentos, porém com uma boa produtividade, ainda que os solos da várzea apresentem pouca fertilização (NODA, 2010). O cultivo da juta e malva se tornou uma atividade exclusiva dos pequenos agricultores, na base da agricultura familiar, ao contrário das propriedades dos seringais e castanhais que se concentravam em poucas mãos (HOMMA, 1998).

O processo dessa cultura ainda segue modelos e técnicas rudimentares, havendo pouca ou nenhuma introdução de tecnologias e modificações nos processos produtivos. As fibras da juta e malva, de acordo com Noda (2010), são utilizadas em larga escala como matéria-prima na confecção de sacaria, na produção de telas e fundos de tapetes. Em um período de forte apelo ecológico, essas fibras têm ganhado importância social e ambiental, como matéria-prima para substituição de plásticos e para a geração de emprego e renda para as 
populações rurais (HOMMA, 2010).

O trabalho nesse tipo de agricultura se constitui de força de trabalho familiar, tendo o homem como chefe da família e organizador do processo produtivo, visto que tal processo ainda nos dias de hoje depende exclusivamente da força de trabalho. É comum a participação de vizinhos, compadres na forma de ajuda mútua, ou até mesmo a troca de dia. No contex to amazônico é comum encontrar a forma de ajuda mútua, sem uma formalização ou regulamentação desse processo, essa forma de ajuda é denominada regionalmente como ajuri ou puxirum, tem o formato de um mutirão.

Destaca-se que todo processo de produção da juta/malva nesses 80 anos é realizado de forma manual/artesanal e insalubre, uma vez que os produtores rurais ficam em média de oito a dez horas por dia submersos com água até a cintura, e vulneráveis ao ataque de animais peçonhentos. No período de maior demanda, os trabalhadores tendem a se dedicar a essa atividade de segunda a domingo, com pouco tempo de intervalo para o descanso. Nesse processo produtivo estão inseridos filhos, mulheres, homens, idosos, todos da família participam direta ou indiretamente. A renda da juta e malva constitui em renda extra, as demais atividades produtivas da agricultura familiar, contribuindo para a aquisição de bens mais duráveis.

De acordo com Fagundes (2002), os campos de sementes de juta estão no município de Alenquer, no Estado do Pará, sua produção é coordenada pela Embrapa da Amazônia Oriental. As sementes de juta são produzidas sob a encomenda do Instituto de Fomento à Produção de Fibras Vegetais da Amazônia - Ifibram, que as repassa para os produtores da fibra. O Governo do Estado do Amazonas, por meio do Instituto de Desenvolvimento do Amazonas - Idam, e firmas particulares. O ciclo de desenvolvimento das fibras é de oito meses, sendo colhidas a partir de julho/agosto. A juta é plantada pelos agricultores a partir de dezembro, com um ciclo de desenvolvimento de cinco a seis meses, sendo colhida entre maio e junho. Os cultivos de sementes de malva estão localizados em Capitão Poço e Bragança, no nordeste do Pará, a sua produção e distribuição também é coordenada pelo Ifibram.

\section{Desenvolvimento Sustentável}

Para falar de desenvolvimento sustentável e seus reflexos para as 
sociedades, vale destacar o conceito de desenvolvimento. Para Diegues (1992), o conceito de desenvolvimento está atrelado diretamente ao conceito de progresso. Este é herdado das correntes positivistas, onde está implícita a ideia de crescimento das sociedades de forma infinita e a geração de cada vez mais riquezas. Nessa visão mecanicista e pautada no conhecimento técnicocientífico, a ciência será o instrumento essencial para desvendar a natureza e colocá-la a serviço do homem, tendo como mola propulsora a industrialização.

A partir da Revolução Industrial no século 18, as indústrias se desenvolveram de forma acelerada, controlando e dominando a natureza, e fazendo uso dos recursos naturais, o que até os anos 60 do século 20 foi considerado normal e necessário para o processo de desenvolvimento, o conhecido progresso da civilização humana. Como assevera Diegues (1992: 2): "A natureza [...] era considerada como um elemento imutável, fonte inesgotável de matéria-prima, e não como sistema vivo com processo e funções próprias". Nesse processo houve nas diversas nações, em especial as desenvolvidas, um grande incremento no desenvolvimento de tecnologias para fabricação de bens duráveis, instalação de grandes indústrias e um crescimento acelerado da classe trabalhadora, que não mais detinham os meios de produção, mas apenas sua força de trabalho para vender ao capitalista. Com o crescimento das indústrias, houve o aumento do uso dos recursos naturais, em especial dos minerais, com destaque para o petróleo, muito utilizado como energia para o processo produtivo nas indústrias. Nesse contexto de crescimento, há também a destruição, aumento das desigualdades sociais, da pobreza, da degradação ambiental, poluição das águas e do planeta.

A degradação ambiental, como afirma Leff (2001), manifestou-se como um sintoma de uma crise da civilização, onde a ciência e o desenvolvimento tecnológico predominaram sobre a natureza. A partir da crise ambiental nos anos 70 , viu-se a necessidade de internalizar o imperativo da sustentabilidade ecológica no processo econômico.

Nesse momento surge o conceito de ecodesenvolvimento que foi, segundo Diegues (1992), introduzido por M. Strong no início da década de 70 como alternativa para a divisão entre economia e ecologia. O ecodesenvolvimento propunha uma nova ética de desenvolvimento, reforçava a necessidade de utilizar os recursos naturais de cada ecossistema de forma comedida, pelos povos locais; tinha como objetivo a melhoria da qualidade de vida dos povos 
e a satisfação das necessidades básicas; o ecodesenvolvimento propunha ainda a descentralização das tomadas de decisões e a solidariedade com as gerações futuras.

Sachs (1974, apudLEFF, 2001: 267) "definiu o ecodesenvolvimento como um estilo de desenvolvimento particularmente adaptado às regiões rurais do Terceiro Mundo fundado na sua capacidade natural para a fotossíntese", o discurso do ecodesenvolvimento promovia uma nova ética da natureza e uma solidariedade diacrônica com as gerações futuras, baseada na conservação dos recursos renováveis e na oposição ao desperdício dos recursos não renováveis.

A partir desse período, iniciam novos debates sobre os usos dos recursos naturais articulados com o processo de crescimento econômico, surgem grupos de estudo e debates em torno da temática do desenvolvimento sustentável, da preservação do ambiente e dos ecossistemas do planeta e a busca de estratégias para crescer economicamente e continuar a garantir a geração de riquezas para as grandes nações. Um grande desafio que está posto ainda nos dias de hoje, que pouco se vislumbra uma solução. Quem assumirá os riscos de tornar a economia um meio e não um fim para o desenvolvimento das sociedades sustentáveis?

De acordo com Corazza (2005), no final dos anos 60 e início da década de 70, a equipe de Dornella Meadows já alertava sobre os riscos que a tecnologia poderia colocar ao ambiente. O debate central foi o fato de que as tecnologias desenvolvidas e aplicadas com objetivo de proporcionar melhor bem-estar à sociedade, como, por exemplo, as tecnologias agrícolas voltadas para o aumento da produção das culturas, com o tempo passariam a trazer consequências indesejáveis, como a contaminação dos alimentos e as doenças advindas dessa contaminação.

Diegues (1992) destaca nesse período da década de 70 o Clube de Roma e em seu livro Limites do crescimento apresentou um panorama sombrio para a humanidade, informações relativas à finitude dos recursos naturais e o contínuo crescimento da população, do consumo e do uso da natureza. Esse grupo anunciava o esgotamento próximo das principais reservas minerais; o aumento da poluição; a degradação dos ecossistemas; a explosão demográfica e a diminuição da qualidade de vida nos países industrializados. Alertava ainda para o falso otimismo, baseado na crença de que a tecnologia poderia solucionar todos os problemas. 
O grupo de Bariloche liderado por Herrera indicou que seria possível a todos os países e regiões o alcance de uma sociedade ideal, sendo que o único modelo para controlar o crescimento da população seria a melhoria de suas condições básicas de vida (CORAZZA, 2005).

Nesse ponto vale destacar a proposta de Herrera, visto que diversas sociedades da Europa alcançaram altos níveis de crescimento e sociedades sustentáveis, em virtude da garantia e da possibilidade da população em ter acesso às melhores condições de vida (saúde, educação, trabalho, habitação) e a condição de fazerem por si próprios suas escolhas, sem estar no controle ou tutela do Estado.

Quanto aos grandes encontros mundiais para a discussão sobre a crise ambiental, tem-se destaque na década de 70 a Conferência de Estocolmo no ano de 1972. Guimarães (1997) afirma que as discussões nessa conferência centraram nos aspectos técnicos relativos à contaminação provocada pela industrialização, no crescimento da população e na urbanização.

A Comissão de Brundtland foi um grupo relevante na discussão sobre a crise ambiental, como assevera Diegues (1992). Essa comissão adotou e definiu o termo Desenvolvimento Sustentável em seus documentos e esse tomou corpo e destaque em toda sociedade. Desenvolvimento sustentável é aquele que satisfaz as necessidades do presente sem comprometer a possibilidade de gerações futuras satisfazerem as suas.

Para Leff (2001), o objetivo principal da Comissão de Brundtland foi preparar o terreno para propor uma política de consenso que articulasse as diferentes visões e interesses dos países, povos e classes sociais, num espaço de conflito como o do desenvolvimento sustentável. Ainda segundo esse autor, a noção de sustentabilidade se configurou como condição para a sobrevivência humana, contudo deveria haver um esforço de todas as nações do mundo. O discurso da sustentabilidade proposto pela comissão defendia o crescimento sustentado, sem uma avaliação sobre a capacidade de o sistema econômico internalizar as condições ecológicas e sociais - de equilíbrio, equidade, justiça e democracia. "O discurso do desenvolvimento sustentável afirma o propósito de alcançar um crescimento econômico duradouro, sem explicar a possível internalização das condições de sustentabilidade ecológica através dos mecanismos de mercado" (Ob. cit., p. 265).

Os resultados apresentados pela Comissão de Brundtland ofereceram 
uma nova perspectiva para a discussão da problemática ambiental e do desenvolvimento sustentável, o que justificou a necessidade da convocação de todos os chefes de Estado do planeta para a Conferência das Nações Unidades sobre Meio Ambiente e Desenvolvimento - ocorrida no Rio de Janeiro em 1992.

Nessa conferência foi elaborada e aprovada a Agenda 21. Esta foi um importante instrumento para orientar uma transição para o desenvolvimento sustentável. A partir desse encontro, a noção de sustentabilidade foi disseminada e se vulgarizou, tornando presente nos diversos cenários sociais, políticos e econômicos, sendo hoje uma linguagem comum, sem fundamentações teóricas que deem o aporte necessário para o seu entendimento.

Guimarães (1997) afirma que sustentabilidade do desenvolvimento obriga a democratização do Estado e não seu abandono ou substituição pelo mercado. O Estado é o único capaz de enfrentar o poder das transnacionais, bem como o complexo processo político presente no comércio internacional. É preciso garantir o acesso ao trabalho, à educação, à moradia, à saúde e a um ambiente livre da contaminação, e ir além, criar espaços para práticas coletivas solidárias de satisfação das necessidades. Destaca ainda a importância de resolver as situações de extrema desigualdade no acesso e distribuição de recursos naturais, econômicos e políticos intra e entre nações, para que dessa forma possamos pensar a sustentabilidade como prática concreta e consciente em nossas sociedades.

O conceito de sustentabilidade e suas variáveis permite avaliar os diversos processos da sociedade, quando está em pauta a relação homem e ambiente. Para tanto, este estudo propôs analisar a relação das dimensões da sustentabilidade apresentadas por Guimarães (1997) e Sachs (2008), com o processo produtivo da juta e malva. A escolha desses dois teóricos é pela proximidade das dimensões por eles discutidas, as quais possibilitam a ampliação da discussão. Ambos apresentam oito dimensões para uma análise da sustentabilidade, em alguns pontos estas se cruzam, outras se complementam. Para Guimarães (1997), a sustentabilidade possui as dimensões relativas à sustentabilidade planetária; ecológica; ambiental; demográfica; cultural; social; política e institucional. Sachs (2008) destaca a sustentabilidade social; cultural; ecológica; ambiental; territorial; econômica; política nacional; política internacional. 


\section{A Juta e a Malva na Perspectiva do Desenvolvimento Sustentável}

O processo produtivo da juta e malva e a fabricação de produtos a partir da fibra, ainda que tenham apelo ecológico e contribuam para uma sociedade mais sustentável, apresenta aspectos que precisam ser mais estudados e melhorados por meio do uso de tecnologias que proporcionem um desenvolvimento sustentável.

A partir das dimensões e critérios de sustentabilidade proposto por Guimarães (1997) e Sachs (2008), faremos uma breve análise da sustentabilidade do processo produtivo dessa cultura. Uma análise mais criteriosa e aprofundada poderia ser foco de uma tese de doutorado, visto o tamanho de informações, literaturas e dados referente às grandes duas temáticas deste estudo: processo produtivo da juta e malva e o desenvolvimento sustentável; contudo, este estudo é apenas um ensaio dessa proposta.

Sustentabilidade social: para Guimarães (1997), a sustentabilidade social está relacionada ao desenvolvimento que tem por objetivo a melhoria da qualidade de vida da população, tendo como critérios básicos a justiça distributiva para o caso de bens e serviços; a universalização da cobertura para as políticas educação, saúde, habitação e seguridade social. Para Sachs (2008), essa dimensão social propõe também uma distribuição de renda justa, o pleno emprego e ou trabalhos dignos que valorizem e reconheçam o trabalhador e lhe proporcionem uma vida decente; igualdade no acesso aos recursos e serviços sociais. No que se refere à juta e malva, verificamos diversos pontos que indicam que o processo produtivo caminha mais para a insustentabilidade do que para a sustentabilidade: no que se refere à justiça social e distributiva, ainda vivemos em país com baixos índices de desenvolvimento humano, o acesso aos serviços sociais como educação, saúde, assistência social são universais, contudo a situação em que tais serviços se encontram demonstram o abandono e a fragilidade das políticas sociais brasileiras, em áreas rurais as problemáticas são ainda maiores, garantido apenas o mínimo para a sobrevivência. Em comunidades pesquisadas encontramos professores trabalhando em séries multisseriadas, em escolas sem a mínima estrutura para o aprendizado; total ausência de profissionais e de instalações na área da saúde; ausência de apoio técnico e conhecimento para manejo da agricultura. Quanto à previdência social, esta não é direito de todos, mas apenas daqueles que contribuem com 
ela, pelo pagamento mensal, seja individualmente ou pelo trabalho com carteira de trabalho assinada. Essa dependência do pagamento impossibilita o acesso para aqueles que vivem em trabalhos sem vínculos empregatícios, informais. O processo produtivo da juta e malva é desenvolvido por intermédio de um trabalho autônomo e precarizado, onde está presente a insalubridade e periculosidade no desenvolvimento das atividades laborativas. $O$ trabalhador fica em média oito horas por dia dentro da água, sujeito a picada de insetos e animais peçonhentos; o trabalho não é reconhecido economicamente, sendo que o trabalhador recebe baixo retorno financeiro em relação ao sofrimento que é para ele tal atividade. Noda (2010) assevera que a cultura da juta e malva se caracteriza pelo uso do trabalho manual, com poucos instrumentos. É comum encontrar durante a safra trabalhadores temporários, que representam a mercantilização das relações de produção e trabalho e a necessidade cada vez maior do dinheiro. Esse processo reproduz o sistema capitalista e suas formas de apropriação do trabalho alheio de forma exploratória e desigual. Nos dias de hoje são cada vez menores o número de jovens que querem continuar nesse processo produtivo, visto o sofrimento dessa labuta, isso pode gerar num futuro próximo uma escassez de mão de obra em tal produção.

Sustentabilidade cultural: para Sachs (2008), esse critério está relacionado a privilegiar a continuidade da tradição, sem deixar de valorizar a inovação; a sociedade deve ter autonomia para criar um projeto nacional integrado e a partir das necessidades nacionais, regionais, deixando de ser servil dos ditames e políticas internacionais; é preciso ter autoconfiança combinada com a abertura para o mundo. Do ponto de vista da dimensão da sustentabilidade cultural, Guimarães (1997) assevera que a base do desenvolvimento reside na manutenção da diversidade e necessidade da integração nacional ao longo do tempo. Garantia dos direitos constitucionais das minorias, em especial a demarcação de território, religiosidade e saúde comunitária, além da introdução de incentivos e direitos de conservação agrícola. Nesse ponto, em relação à juta e malva, entende-se que se deve respeitar as diversidades, os saberes e tradições populares, sendo eles pontos de destaque para a construção de políticas públicas. Criar políticas econômicas que privilegiem a produção local, segundo Chiara (2012), a invasão de produtos importados atinge as indústrias brasileiras de sacos de juta, que passam a demitir trabalhadores, perdemos na competição com os produtos importados em função da pesada carga 
tributária, encargos trabalhistas e deficiências na infraestrutura. Na busca da competitividade, as relações de trabalho são desumanas, há desenvolvimento de tecnologias que não respeitam os limites dos recursos naturais, internalizamse políticas econômicas e sociais que não respondem às necessidades locais e perde-se parte ou a totalidade das identidades locais, dos costumes e saberes herdados das gerações antepassadas, em troca do que é moderno, mas não necessariamente útil.

Sustentabilidade ecológica: para Sachs (2008: 86), esse critério de sustentabilidade está relacionado à "preservação do potencial do capital natureza na sua produção de recursos renováveis; limitar o uso dos recursos não renováveis". Para Guimarães (1997), essa dimensão refere-se ao desenvolvimento e ao crescimento integrado com a conservação e uso racional do estoque de recursos naturais incorporados às atividades produtivas. No que se refere ao uso de recursos naturais renováveis, a taxa de utilização deveria ser equivalente à taxa de recomposição; os custos de recomposição dos recursos renováveis devem ser incluídos nos investimentos no processo de exploração. Quanto ao uso dos recursos não renováveis, a taxa de utilização deveria estar relacionada à taxa de substituição dos mesmos recursos, durante o tempo previsto para o seu esgotamento; deveria haver um limite no ritmo de utilização desse recurso, segundo o mesmo ritmo de desenvolvimento ou do descobrimento de novos substitutos; os investimentos utilizados na exploração de recursos não renováveis devem ser proporcionais aos investimentos destinados à busca de substitutos. Nesse aspecto, entende-se que a cultura da juta e malva segue modelos de plantações numa lógica semelhante à da indústria, não é algo nativo, em especial a juta, em que foi realizada uma adaptação dessa cultura na região. A atenção no processo produtivo da juta e malva é em relação aos cuidados para evitar o desmatamento para o plantio dessa cultura, de forma a aumentar a produção, prejudicando o plantio de outras culturas que são fundamentais para a sobrevivência dos povos da Amazônia. Ainda não se observa o uso de produtos agrotóxicos que poderiam prejudicar o solo e a saúde dos produtores, nesse sentido as cheias dos rios tem sido bons fertilizantes para o preparo da terra para o plantio da juta.

Sustentabilidade ambiental: Sachs (2008) refere-se a esse critério como sendo o respeito e o destaque para a capacidade de autodepuração dos ecossistemas naturais. Para Guimarães (1997), essa dimensão está relacionada com a 
manutenção da capacidade de carga dos ecossistemas, ou seja, a capacidade de que a natureza possui para absorver e recuperar das agressões antrópicas; um ponto importante nessa dimensão seria a conversão industrial com foco na redução da entropia e de forma a privilegiar a conservação de energia e o uso de fontes renováveis. Nessa dimensão, vale destacar no plantio da juta e malva o tempo de pousio da terra para o início da plantação e colheita de uma nova safra, como ainda a produção da juta e malva não alcançaram grandes patamares de produção, pode-se afirmar que não há degradação do ambiente nas áreas de cultivo destas.

Sustentabilidade demográfica: nessa dimensão, Guimarães (1997) põe em foco que as taxas de crescimento devem ser analisadas em conjunto com as taxas do aumento da produtividade, da PEA - população economicamente ativa, além das taxas de crescimento da população, sua composição etária e outras variáveis demográficas. Há ainda a necessidade de se adequar às tendências observadas ou esperadas de migração e de distribuição espacial da população com as políticas de crescimento econômico regional (política industrial, agrícola). Nesse aspecto, o que se observa é uma tendência da migração, em especial dos jovens da área rural para a urbana, em busca de melhores trabalhos, renda e condições de vida. Em uma atividade produtiva insalubre e mal remunerada, como a juta e malva, tal tendência parece ser ainda maior. Isso necessitaria de maiores estudos para verificar dados relativos à migração daqueles que trabalham nessa cultura ou possivelmente poderiam trabalhar para as regiões urbanas.

Sachs (2008), diferentemente da sustentabilidade demográfica proposta por Guimarães (1997), destaca a dimensão territorial que indica como ponto de análise um olhar sobre as configurações urbanas e rurais que deveriam ser mais balanceadas; hoje se observa um maior investimento para os recursos e serviços para as áreas urbanas em prejuízo das áreas rurais. Esse ponto acaba por contribuir para as variáveis demográficas, havendo uma maior locomoção dos povos em busca de melhores condições de vida. Dois outros pontos de destaque do autor é a superação das disparidades inter-regionais e a busca de estratégias seguras para o desenvolvimento ambiental, como a conservação da biodiversidade pelo ecodesenvolvimento.

Sustentabilidade politica: Guimarães (1997) assevera que o desenvolvimento está vinculado ao processo de construção da cidadania e a busca de garantir a 
incorporação plena dos indivíduos ao processo de desenvolvimento. Propõe a democratização da sociedade, que é o fortalecimento das organizações sociais e comunitárias, a redistribuição de recursos e de informação, aumento da capacidade de análise de suas organizações e capacitação para a tomada de decisão. É destaque também a democratização do Estado que implica na abertura do aparato estatal ao controle do cidadão, a reatualização dos partidos políticos e dos processos eleitorais e a incorporação do conceito de responsabilidade política na gestão pública. Nesse aspecto, Sachs (2008) traz entre seus critérios de sustentabilidade o critério da política tanto a nacional como internacional; contudo, coadunando com a análise de Guimarães, é a política nacional que mais se aproxima da dimensão da sustentabilidade política. Para Sachs, esse critério refere-se à democracia como a apropriação universal dos direitos humanos; a capacidade do Estado em implementar um projeto nacional de desenvolvimento em parceria com todos os empreendedores; e uma significativa coesão social. Articulando essa dimensão com a produção da juta e malva, observa-se que não só essa cultura se põe num grau de insustentabilidade, como toda a agricultura familiar. Ainda são escassos e frágeis os acessos desses cidadãos aos direitos sociais e humanos. Esses direitos se materializam por meio de políticas públicas, e no que se refere à produção da juta e malva, tendem a ser pontuais. Podemos citar a política de garantia de preços mínimos, que este ano ficou estabelecido em $\mathrm{R} \$ 1,77 / \mathrm{kg}$, essa política tem por objetivo garantir a sustentação dos preços e apoio à comercialização. Segundo informações de Estevam (2012), a definição dessa medida de preços mínimos é para amenizar os efeitos negativos das enchentes dos rios da região do Amazonas nos primeiros meses do ano, de forma a reduzir as perdas dos agricultores. O governo do Estado, como medida, também entra com um subsídio de mais de $\mathrm{R} \$ 0,20$ por quilo e a garantia de que se a indústria pagar menos, o produtor pode vender para a Conab, por intermédio do escritório do Idam. Mesquita (2012) destaca que um incentivo ao desenvolvimento das indústrias de fiação e tecelagem, do Polo Industrial de Manaus, é a legislação do governo estadual, que, por meio da Lei n. ${ }^{\circ} 2.826 / 03$, concedeu a isenção total de ICMS para os fabricantes de fios, telas e sacos de juta e malva. Estas são políticas importantes, contudo é preciso pensar em políticas que garantam a saúde do trabalhador, o trabalho digno e decente, o uso de tecnologias limpas que contribuam para uma melhor produtividade e ações que colaborem 
para o fortalecimento das organizações comunitárias, dando-lhes autonomia e condições/conhecimentos para a tomada de decisões. Um último ponto, mas não menos importante, é o desenvolvimento da gestão pública participativa, onde o cidadão faz parte das esferas tomadoras de decisão sobre o futuro econômico e social de suas regiões.

Sustentabilidade política internacional: Sachs (2008) aponta esse critério, que Guimarães (1997) irá chamar de sustentabilidade planetária. Para o primeiro autor, é necessário um eficaz sistema de prevenção de guerra a ser promovido pela $\mathrm{ONU}$, de forma que garanta a paz e promova a cooperação internacional; um acordo Norte-Sul de codesenvolvimento, que se baseie no princípio de igualdade e compartilhamento da responsabilidade em favorecer o parceiro mais fraco; um controle institucional efetivo do sistema internacional e financeiro; controle institucional na aplicação do Princípio da Precaução na gestão do meio ambiente e dos recursos naturais; prevenção dos efeitos negativos das mudanças globais; proteção da diversidade biológica e cultural; gestão do patrimônio global, como herança comum para a humanidade; um sistema efetivo de cooperação internacional nos aspectos relativos ao desenvolvimento da ciência e da tecnologia; eliminação parcial do caráter de commodity da ciência e da tecnologia. Guimarães (1997), quanto ao critério da sustentabilidade planetária, destaca que o desenvolvimento está diretamente relacionado com as questões além das fronteiras do Estado-nação, e a necessidade de revisão dos processos globais de degradação ecológica e ambiental. A autora dá ênfase aos aspectos relacionados à preservação da biodiversidade e da vida no planeta, onde se fazem urgentes ações como a redução da emissão de gases que contribuem para o aquecimento global; redução das taxas de desmatamento; aumento das áreas reflorestadas; redução das taxas de extinção de espécies e preservação de habitats críticos importantes para a manutenção do patrimônio biogenético do planeta; mudanças na matriz industrial, científica e tecnológica, de forma a incorporar e intensificar a difusão de tecnologias baseadas no uso da biodiversidade. Para que essa dimensão se desenvolva é preciso a parceria dos organismos institucionais e Estados-nações para o preservação da vida no planeta. Ações e encontros como as Conferências das Nações Unidades para o Meio Ambiente, como a Rio 92 e a Rio +20 podem ser espaços e momentos importantes para a concretização de acordos que venham a beneficiar, em especial, os países em desenvolvimento. Quanto à produção da juta e malva, é 
preciso valorizar a produção local, tendo como estratégia primária o aumento dos impostos aos produtos importados, em especial os produtos oriundos da Índia e Bangladesh, os maiores produtores de juta no mundo. Segundo Mesquita (2012), as indústrias têxteis do Estado do Amazonas estão em desvantagem competitiva, visto que as importações cada vez mais se intensificam por conta da política cambial vigente. Há fábricas eficientes no Amazonas, mas não há como competir com os indianos porque os custos nacionais são maiores. Nesse aspecto, é relevante pensar em políticas e em acordos internacionais que primam pela produção e indústria locais.

Sustentabilidade econômica: para Sachs (2008), esse critério refere-se ao desenvolvimento intersetorial equilibrado; a segurança alimentar; as condições para a contínua modernização dos instrumentos de produção; maior autonomia para a pesquisa científica e tecnológica e, por fim, a inserção soberana na economia internacional. Para Guimarães (1997), a sustentabilidade econômica está inserida na sustentabilidade social, sendo que a política econômica deve privilegiar os mercados nacionais e a complementariedade regional que esteja orientada à satisfação das necessidades básicas e à diminuição das desigualdades sociais, gerando maior e melhor distribuição de riquezas. Propõe o desenho de políticas tributárias que promovam a redistribuição de recursos nacionais do centro às periferias e a justiça social que se refere à revitalização do poder local, com a transferência efetiva de recursos e ativos que lhe dê condições de ter autonomia. A política econômica na contemporaneidade de nenhuma forma tem atuado para diminuir ou proporcionar mudanças na distribuição da riqueza produzida, este tem sido um dos pontos mais questionáveis nas políticas para o desenvolvimento sustentável, como garanti-lo numa sociedade capitalista, que acumula e que produz riquezas, sem ao menos ponderar quanto as consequências desse processo para o ambiente. Analisa-se o crescimento de um país a partir do PIB - Produto Interno Bruto, contudo não se têm dados quanto às consequências desse crescimento, quanto se degradou o ambiente, quanto foi desmatado ou quanto de poluentes foram jogados para o ar, quantos trabalhadores foram explorados ou ficaram à margem da sociedade? A proposta de desenvolvimento sustentável criada desde a Comissão de Brundtland trouxe uma série de responsabilidades para a sociedade civil, porém nenhuma mudança na lógica capitalista. De acordo com Barros (2012), a estimativa da safra de juta e malva, para o ano de 2012, é de 12 mil toneladas, um ponto 
de atenção este ano foram as enchentes: o rio subiu rápido, dificultando ou até mesmo impedindo o juticultor de colher sua plantação, muitos dos agricultores, que têm financiamento do Pronaf, terão dificuldades de pagar seus financiamentos. Estão sendo tomadas providências pela Secretaria de Produção Rural do Estado do Amazonas junto ao Ministério da Agricultura, para adotar medidas de proteção ao trabalhador, desde o seguro agrícola, a prática do preço mínimo e renegociação de dívidas e empréstimos juntos aos bancos.

O cultivo da juta e malva no Estado do Amazonas é resultado do esforço de centenas de agricultores familiares, pesquisadores e empreendedores, que vislumbram a possibilidade de que essa cultura se torne parte importante da economia da região. Para tanto, fazem-se necessárias políticas públicas e econômicas que garantam a justiça social, a redistribuição equitativa das riquezas produzidas nacionalmente, a criação de políticas tributárias que valorizem a produção nacional em detrimento ao produto importado, em especial aqueles oriundos de países que degradam o ambiente e exploram o trabalhador; o empoderamento da população, com destaque os agricultores familiares, para que tenham condições de negociar, tomar decisões e se organizar politicamente para a preservação e garantia de seus direitos constitucionais e tenham capacidade de lutar por melhores condições de trabalho e de vida.

\section{Considerações Finais}

O desenvolvimento sustentável é um grande desafio posto às sociedades contemporâneas. Vivemos no cotidiano as contradições desse desafio, somos chamados a consumir, a contribuir para o desenvolvimento econômico, reduzem-se os juros e os impostos, e ao mesmo tempo são cada vez mais alarmantes os dados referentes à degradação ambiental, ao aquecimento global, a poluição do ar, ao destino insustentável de nossos lixos, resultado de nosso consumo insano.

Então, discutir sobre essa temática é algo precípuo para nós, pesquisadores, para ter um entendimento que vá além do senso comum, do que é o desenvolvimento sustentável, para de fato entendermos a sua relevância e os vieses econômicos, políticos e sociais por trás desse termo. É possível pensar o desenvolvimento sustentável e suas dimensões nas diversas esferas da 
vida social, nas questões sociais e ambientais, e analisarmos quão sustentáveis ou insustentáveis estão os processos, o modo de vida, as condições de trabalho e as atividades produtivas. Foi isso que tentamos ensaiar neste estudo, fazendo uma breve discussão sobre o processo produtivo da juta e malva na perspectiva do desenvolvimento sustentável.

Dessa feita, concluímos que o processo produtivo da juta e malva apresenta fragilidades em suas diversas dimensões, o que pode gerar a insustentabilidade dessa cultura. Destacamos no aspecto social que é ausente a justiça social, o trabalho decente e inclusivo; os trabalhadores da juta e malva vivem à revelia dos direitos trabalhistas e previdenciários, labutam diariamente em uma atividade insalubre que traz sérias consequências à sua saúde; não há incentivo para o jovem trabalhador desenvolver esse cultivo, em razão do sofrimento do trabalho e do pouco retorno financeiro, gerando a insustentabilidade demográfica, a migração do jovem para a cidade, quando não de toda a família em busca do trabalho e de melhores condições de vida. Contudo, na cidade encontra a pauperização, as precárias condições nas áreas periféricas, o trabalho sem reconhecimento legal e uma maior exploração dele, ficando mais sujeitos à apropriação do capital e às desigualdades sociais. Nos aspectos econômicos e político, são poucos os incentivos para o desenvolvimento do plantio desse cultivo e a sua continuidade, é mais o esforço do trabalhador do que resultado das medidas de garantia de preço mínimo, da entrega das sementes aos juticultores ou da compra de uma parte da produção para garantir os preços. Não há políticas tributárias de forma a tarifar os produtos importados de forma a valorizar a produção local e os investimentos em tecnologias e recursos para o aumento e melhoria da produção da juta e malva na região.

Este breve estudo nos inquieta e nos instiga a um aprofundamento da leitura nessas temáticas e na articulação entre elas, o que poderá ser desenvolvido em outra produção ou ficar de incentivo para outros pesquisadores e visionários que acreditam no valor dessa cultura na região do Amazonas.

\section{Referências}

BARROS, Cimone. Cheia dos rios prejudica a produção de juta no AM. http:// acritica.uol.com.br. Acesso em: 1. ${ }^{\circ}$ de junho de 2012. 
CHIARA, Marcia. Saco de juta do Pará perde mercado para Índia e Bangladesh. http://www.fazenda.gov.br/resenhaeletronica/. Acesso em 1. ${ }^{\circ}$ de junho de 2012.

ESTEVAM, Raimundo. Produtores de juta/malva da Amazônia podem contar com apoio da PGPM. http://www.agricultura.gov.br. Acesso em: 1. ${ }^{\circ}$ de junho de 2012.

CORAZZA, Rosana Icassatti. Tecnologia e meio ambiente no debate sobre os limites do crescimento: notas à luz de contribuições selecionadas de GeorgescuRoegen. Revista Economia. Brasília (DF), v. 6, n. o 2, p. 435-461, jul./dez., 2005.

DIEGUES, Antonio Carlos S. Desenvolvimento sustentável ou sociedades sustentáveis. São Paulo em Perspectiva. São Paulo, v. 6, n. ${ }^{\text {os }}$ 1-2, 1992.

FAGUNDES, Maria Helena. Sementes de juta e malva: algumas observações. http://www.conab.gov.br/conabweb. Acesso em: 1. ${ }^{\circ}$ de junho de 2012.

GUIMARÃES, Roberto P. Desenvolvimento sustentável: da retórica à fórmula de políticas públicas. In: BECKER, Bertha; MIRANDA, Mariane. A Geografia política do desenvolvimento sustentável. Rio de Janeiro: Editora UFRJ, 1997.

HOMMA, Alfredo K. Oyama. Amarônia: meio ambiente e desenvolvimento agrícola. Editor: Alfredo K. O. Homma. Brasília: Embrapa - SPI; Belém: Embrapa - Cpatu, 1998.

A imigração japonesa no Estado do Amazonas: a expansão da juta no médio e baixo Solimões. In: WITKOSKI, Antonio Carlos; FERREIRA, Aldenor da S.; HOMMA, Alfredo K. Oyama; FRAXE, Therezinha de J. P. (Orgs.). A cultura de juta e malva na Amazônia Ocidental: sementes de uma nova racionalidade ambiental? São Paulo: Editora Annablume, 2010.

IBGE. www.ibge.org.br. Acesso em: 10 em outubro de 2010.

LEFF, Enrique. Estratégias do ecodesenvolvimento e do desenvolvimento sustentável: racionalização do capital ou reapropriação social da natureza. In: LEFF, Enrique. Saber ambiental: sustentabilidade, racionalidade, complexidade, poder. Petrópolis, RJ: Vozes, 2001.

MESQUISTA, Priscila. Juta nativa perde mercado para a Índia e Bangladesh. Cafeicultura a revista do agronegócio. http://www.revistacafeicultura.com.br 
NODA, Sandra do Nascimento. Agricultura familiar amazonense: mobilidade e relações de trabalho na produção de juta e malva. In: WITKOSKI, Antonio Carlos; FERREIRA, Aldenor da S.; HOMMA, Alfredo K. Oyama; FRAXE, Therezinha de J. P. (Orgs.). A cultura de juta e malva na Amazônia Ocidental: sementes de uma nova racionalidade ambiental? São Paulo: Editora Annablume, 2010.

PINTO, Ernesto Renan Melo de Freitas. A constituição histórica da produção mercantil simples no Estado do Amazonas e a cultura da juta. In: WITKOSKI, Antonio Carlos; FERREIRA, Aldenor da S.; HOMMA, Alfredo K. Oyama; FRAXE, Therezinha de J. P. (Orgs.). A cultura de juta e malva na Amazônia Ocidental: sementes de uma nova racionalidade ambiental? São Paulo: Editora Annablume, 2010.

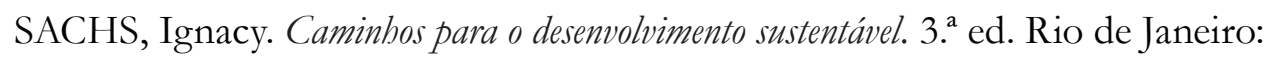
Garamond, 2008. 